\title{
Nurse leaders' perceptions of the impact of their participation in a reflective practice program
}

\author{
Mélanie Lavoie-Tremblay, Guylaine Cyr, Gilbert Primeau, Thalia Aube \\ Ingram School of Nursing, McGill University, Montreal, Quebec, Canada
}

Received: November 2, 2018

DOI: $10.5430 /$ jnep.v9n4p38
Accepted: November 29, 2018 Online Published: December 7, 2018

URL: https://doi.org/10.5430/jnep.v9n4p38

\begin{abstract}
Since 2003, a university healthcare centre in Quebec (Canada) has offered its nursing leaders access to a long-term professional development program focusing on skills in Reflective Practice (RP). This program is based on teaching nursing leaders to interpret and reframe difficult, emotionally-charged situations they encounter on a regular basis, so they can improve their interpersonal interactions with their colleagues, patients, and patients' families. This article describes the results of a qualitative study conducted in 2018 with 18 nursing leaders who participated for at least three years in the RP program. Participants were asked to describe their understanding of the RP approach, key learnings from the program, and parts of the training they found most valuable. They were also asked to define or share the program's impact on their professional practice and leadership skills. It was found that the participants view RP as a useful tool for understanding and improving their interactions with others, and that it had led to concrete improvements in their interpersonal and leadership skills. Several of the positive changes described by participants are rarely described in other studies about the use of RP as a professional development tool in a clinical nursing setting. The results suggest that when nurse leaders have participated for several years in an RP program, they experience different benefits than front-line staff with less long-term participation.
\end{abstract}

Key Words: Reflective practice, Nursing leadership, Professional development

\section{INTRODUCTION}

Being a clinical nurse leader is a complex task requiring multiple competencies. Nurse leaders are charged with maintaining and improving quality of care, managing limited resources, and collaborating with staff from a variety of professional disciplines, generational cohorts, and cultural backgrounds, all while adapting to constant changes and technological advances. ${ }^{[1]}$ The nurse leader of today must be a coach, teacher and facilitator, and must exercise leadership in clinical care, management, education, research, and policymaking. ${ }^{[1,2]}$ These roles all require the interpersonal skills to collaborate effectively with colleagues, patients, and their families, even more so during extremely difficult and emotional situations. ${ }^{[3,4]}$

In an effort to develop these interpersonal skills within their leadership structure, a healthcare center in Montreal (Canada) has collaborated with expert facilitators to implement a longterm Reflective Practice (RP) program. ${ }^{[4]}$ Based on the work of Argyris and Schön, ${ }^{[5-8]}$ Schwarz, ${ }^{[9]}$ and Kegan and Lahey, ${ }^{[10,11]}$ this program teaches its participants how to identify the unspoken values and assumptions with which they frame their interactions in the workplace, and how to reframe these interactions with a mindset that is more transparent, compassionate, and open to the views of other people. ${ }^{[4]}$

\footnotetext{
${ }^{*}$ Correspondence: Mélanie Lavoie-Tremblay; Email: Melanie.lavoie-tremblay @mcgill.ca; Address: Ingram School of Nursing, McGill University,
} Montreal, Quebec, Canada. 
By using this process, nurse leaders trained in RP can learn how to improve their interactions with others, leading to better outcomes for the organizations in which they work, and ultimately, patients and their families.

In the last two decades, RP has become an important concept within the discipline of nursing; however, despite widespread use of the term in the literature, empirical research on its use in a nursing context is not well-developed. ${ }^{[12]}$ Consequently, it remains to be seen how to best develop RP in a clinical nursing setting, and how it alters the practice and leadership capabilities of the nurse leaders who are trained in its principles.

In a recently-published article, Smith and colleagues ${ }^{[4]}$ describe the development and implementation of the RP program in this organization. Implemented in 2003, the program has been used to train 37 facilitators among the organization's nurses, and it currently has approximately 120 nurse leaders who attend monthly RP meetings. To date, there has been no formal research looking at how these participants perceive the program's impact on their leadership capabilities and their professional development. By exploring the perspective of long-time participants in the program, who work in a setting where RP has strong institutional support, it will be possible to shed light on how RP principles and techniques can be applied among nurse leaders.

\subsection{Purpose of the study}

The aim of this study was to explore nurse leaders' perceptions of the impact of their participation in the RP Program.

\subsection{Study questions}

The questions were:

(a) What is nurse leaders' understanding of the RP approach?

(b) How they apply RP principles in their work?

(c) What is the impact of the RP program on their leadership capability?

Respondents were also asked about the maintenance of the RP program for future generations of leaders and for their suggestions for improving and expanding the program.

\subsection{Principles of reflective practice}

This section will provide a brief explanation of the principles underlying the RP program, mainly to provide context for discussing the results of the study. A more extensive explanation of RP can be found in the work of Smith et al. ${ }^{[4]}$ The term "reflective practice" was coined by Donald Schön. ${ }^{[6]}$ According to Schön, professional practice is more than the application of theories to solve problems; it involves reflection-in-action - a process of framing (naming) the prob-

Published by Sciedu Press lem, acting to solve it, and monitoring the consequences. In reflecting on their practice, one engages in "reflectionon-action" where one reviews how they were thinking "in action" in order to behave as they did.

One of the essential elements of RP is the concept of theories of action, a framework developed by Argyris and Schon. ${ }^{[5]}$ According to this framework, theories of action are the reasoning behind a person's behavior, and they can be divided into two categories: espoused theories, a person's stated rationale for their actions, and theories-in-use, the actual reasons for their behavior. ${ }^{[5]}$ There is often a discrepancy between someone's espoused theory and their theory-in-use, between what they say they do and what they actually do, but they are not consciously aware of this incongruity.

The RP framework posits that most people unknowingly approach discussions with a theory-in-use that is counterproductive, especially when they are in situations they perceive as threatening, such as an emotionally-charged interpersonal situation; Schwarz calls this theory-in use the Unilateral Control Model Mindset (UCM) ${ }^{[9]}$ The underlying assumptions of the UCM are:

- I understand the situation; those who disagree don't.

- I am right; those who disagree are wrong.

- My motives are pure; those who disagree have questionable motives.

- My feelings and behaviors are justified.

- I am not contributing to the problem. ${ }^{[9]}$

These assumptions have a corresponding set of values:

- Win, don't lose

- Be right

- Minimize expression of negative feelings

- Act rational. ${ }^{[9]}$

These underlying values and assumptions lead to counterproductive behavior that inhibits effective teamwork and productive problem-solving. The UCM ultimately leads to a degradation of work performance, collaborative relationships, and individual well-being. ${ }^{[9]}$

However, through a process of reflective practice, people can learn to replace this mindset with one that is committed to valid information, informed choice, and collaboration, known as the Mutual Learning Model Mindset (MLM). ${ }^{[9]}$ The assumptions underlying the MLM are:

- I have information; so do others

- Each of us sees things others don't

- Differences are opportunities for learning

- People may disagree with me and still have pure motives

- I may be contributing to the problem. ${ }^{[9]}$ 
The accompanying values of the model are (a) transparency; (b) curiosity; (c) accountability; (d) informed choice; and (e) compassion. ${ }^{[9]}$ By adopting a MLM mindset, problems can be resolved more efficiently and effectively. ${ }^{[13]}$

\subsection{Reflective practice program}

The RP program takes place at a healthcare center in Montreal, Canada. The program began in 2003 and included two coaches training seven nurse leaders on how to facilitate RP meetings. The purpose of these meetings was to provide dedicated time to reflect on challenging work situations, with the facilitators providing guidance on the proper use of RP techniques. ${ }^{[4]}$

Participants in the RP program are grouped according to their respective roles, such as Nurse Manager, Assistant Nurse Manager, or Clinical Nurse Specialist. Overall, the program reaches about $50 \%$ of nursing leadership at the healthcare center. The approximate participation rate by job title is as follows:

- Nurse Manager: 71\%;

- Clinical Nurse Specialists: 96\%;

- Nursing Professional Development Educators: 82\%;

- Assistant Nurse Managers: $25 \%$.

RP groups generally consist of 6-8 members, though attendance varies from session to session. Each RP meeting lasts for 90 minutes. During each session, the group members convene to discuss and re-evaluate difficult cases using RP techniques, following the general format outlined below (adapted from Smith et al. ${ }^{[4]}$ and Argyris ${ }^{[8]}$ ):

- A group member presents a challenging situation including:

- A description of the "problem";

- Steps taken to resolve it;

- What they said and what the other person said;

- Thoughts and feeling they had but did not express; and

- What help they would like.

- The group reflects on the situation using the UCM to identify where and how any breakdowns in communication occurred.

- The group engages in a role-play of the situation, using the MLM to frame and analyze what is going on. With the help of the facilitators, the group tries to identify statements that the presenting member could have used to address the problematic situation more effectively.

- The group reflects on the session, and whether or not it addressed the presenting group members' needs.
The purpose of the meetings is to identify where the presenting member has used the UCM as their theory-in-use, and to demonstrate how to apply the MLM to the same situation in order to produce a more satisfactory result.

\section{Methods}

\subsection{Design}

A qualitative-descriptive design was used in this study. Qualitative descriptive design is widely used by managers and practitioners to obtain answers to specific questions related to practice. ${ }^{[14]}$

\subsection{Setting and participants}

A purposive sampling approach was used to recruit 18 nurse leaders involved in the RP groups. All individuals had to meet the selection criteria of (a) at least 3 years' experience in the RP program (to have had enough time to learn about RP, practice and reflect); (b) experience applying RP skills learned from their participation in the program; (c) willingness to discuss the impact RP skills and theory have had on their practice and leadership; and (d) available during the two-month interview period. Participants were introduced to the study via email by the study decision-maker, who manages and supports the RP program. Those who signed up for the study were then contacted individually by a research assistant, who inquired if they were interested in participating in an individual audio-recorded interview.

In total, 18 participants were recruited out of a possible 120 from March 2018 to April 2018. Four (22.2\%) of participants were RP facilitators, five $(27.8 \%)$ were Clinical Nurse Specialists, three $(16.7 \%)$ were nursing professional development educators, two (11.1\%) were Nurse Practice Consultants, four (22.2\%) were Nurse Managers, three (16.7\%) were Assistant Nurse Managers, and one (5.6\%) was classified as "other". In terms of education level, two (11.1\%) possessed a $\mathrm{PhD}$, thirteen $(77.2 \%)$ had a master's degree, two $(11.1 \%)$ had a bachelor's degree and one $(5.6 \%)$ had a technical degree. On average, the participants had 27.33 years ( $\min 8$; $\max 37$ ) of nursing experience. Participants had participated in the RP program an average of 8.7 years (min 3 ; $\max 15)$. Sixteen $(88.9 \%)$ of participants were female and two $(11.1 \%)$ were male. Not all participants were willing to state their age, but among those who did $(\mathrm{N}=11)$, the average age was 46 years old.

\subsection{Ethical considerations}

Ethical approval for the study was obtained from the Institutional Review Board of the McGill University Faculty of Medicine (2018-4361). The interviewer reviewed a written consent form with each participant, and written consent was 
obtained from all participants before beginning the interview. The consent form informed participants about the study procedure, the purpose of the study, and that their participation was voluntary. The consent form also explained the right to withdraw at any time and the measures that would be taken to ensure confidentiality.

\subsection{Data collection}

Semi-structured individual interviews were conducted during work hours at a location convenient to the participant. All interviews were conducted by a research assistant, with each interview lasting approximately 30 minutes. Interviews were conducted in either English or French, and each interview was audio-recorded and then transcribed. A semi-structured guide with a series of questions to be explored with the participant was used. The main themes addressed included the nursing leaders' understanding of the RP approach, their learnings from the program, how they have applied these learnings in their work, and its impact on their leadership capability. To provide background information about the participants, a socio-demographic questionnaire was completed by each participant at the end of each individual interview.

\subsection{Data analysis}

The data generated by open-ended questions were analyzed using a method proposed by Miles and Huberman. ${ }^{[15]}$ This method of qualitative data analysis consists of three concurrent streams of activities: condensing the data, data display, and elaboration and verification of the data. Original data was condensed by generating codes and categories. ${ }^{[15]}$ Open coding occurred as the researcher reviewed transcripts and field notes line-by-line, highlighting and extracting sections that touch the participants' perceptions. Categories were then formed by clustering codes which referred to similar concepts. Elaboration and verification of the data was done through discussion and review with the other researcher. Descriptive statistics were generated through Excel to describe the socio-demographics of the sample.

\section{FINDings}

Participants' responses were analyzed for common themes about their learnings from the RP program, the concepts that they found the most useful, how their participation has affected them on a personal and professional level, and its impact on their leadership capabilities. Several common themes were identified in the participants' comments.

\subsection{Perceptions of reflective practice}

According to the participants, the RP approach is a set of principles by which they learned to better understand and manage their actions and interactions with others, in order to

Published by Sciedu Press optimize their social skills and communication skills. One participant described RP thusly:

It is a conceptual model with values in relation to communication. How to communicate more easily within a team, and how to be more efficient in your communication, to be more effective and to transmit the message and to understand what other people think. (RP8)

RP was characterized by all participants as a systematic way of thinking, and a technique that can be used for understanding and resolving difficult interpersonal situations:

Well, the RP it's a way of thinking, of organizing your thoughts around critical events that you want to analyze and see from different angles... to use a learning framework to try to solve the issue. (RP14)

\subsection{Learnings acquired thanks to reflective practice pro- gram}

The MLM and its values (Transparency, Curiosity, Compassion, Responsibility, Informed Choice), the "ladder of inference", and the "Bully" Triangle were the learnings that were mentioned by all of the participants.

There's the ladder of inference... you're supposed to be at the bottom - but there's certain conversations you'll have with people that right away your back is up the wall and you're frustrated... [RP] makes you go: okay, take a deep breath, think, always approach from curiosity. Why is the person saying that? It's really trying to stop me, anybody, from making the assumption and then going into the conversation with the assumption.... to take some time, to reflect a bit before responding. (RP12)

Frequent mention was made of the core values of the MLM:

I think the core values... especially transparency and curiosity, compassion as well... it's not compassion in terms of empathy or feeling sorry for the other person, but to really temporarily suspending judgment... and thinking: okay, the other person... might be coming at it from a completely different place. And so, to try and be able to look at it from another point of view. (RP6)

The majority of participants estimate to have acquired skills in the analysis and management of situations and emotions, of interacting with others, of approaching situations from a 
more effective frame of mind, as well as improved listening skills. One participant spoke of how RP pushed them to acknowledge how their behavior may contribute to difficult situations, saying "RP, for me, it's a toolbox, or it's a tool in a toolbox, which forces us to look at how we contribute as individuals to an interaction, to a problem" (RP1). Another participant talked about how RP enabled them to listen more effectively and dispassionately, "it gives me a framework that allows me to listen to what is being said without reacting emotionally sometimes if emotions come into play" (RP9-NM).

Interviewees also spoke of the general education benefit of being placed in the RP program with people from the same organizational level and job type. For almost all of the participants, being grouped by job type facilitated the sharing of common experiences and the acquisition of learning. Participants saw value in being grouped with people with similar jobs as them, "because we are on the same level of work and our role and responsibilities... the others who have already experienced the same situation or have suggestions, they share their expertise, their experience... we learn from the people around us" (RP13).

\subsection{Impact of learnings for the participant on a profes- sional level}

The participants noted different positive impacts of RP learnings in their work. All of them claimed to have improved their professional and interprofessional communication skills thanks to the program. One participant noted that RP improved their communication with patients and their families as well, not just colleagues.

For the majority of participants, the program permits them to be proactive, to reflect before acting: “...maybe I think more before I have certain conversations.... Mentally, I'm prepared" (RP12). It also gives them a more global vision of their interactions with others, enabling a more comprehensive understanding of the situation. One participant described how they use RP principles to notice when they start becoming defensive or rigid in their thinking:

I think, 'you're not right, me, I am right.' Then, if we go back to the principle of curiosity, to try to understand the other person, it allows me to have better interactions with the people around me, and to be more diplomatic and to work better as a team. (RP2)

For half of the participants, the program optimizes the quality of life at work, and some add that it supports collegiality and improves the sense of belonging and team spirit. One of the respondents saw this translating into a better experience for patients as well, stating "I think a unit that has good communication, people are happy, people are comfortable, it's going to be better patient care" (RP12). Another noted that their colleagues are more eager to collaborate with them, thanks to their level of transparency:

But I think one of the reasons people work with me is that they know [the RP skills] I have. I do not have a hidden agenda ... I'm not interested in playing games, I'm not interested in winning. I am interested in what we are doing together. (RP1)

\subsection{Concrete examples of the use of RP techniques in the workplace}

Several respondents gave specific examples of how they have applied their RP learnings in their professional life. One of the study participants recounted how, when encountering resistance from a physician on a plan for distributing caseloads, they were able to use the RP values of transparency and curiosity to resolve their disagreement:

I didn't understand [the physician's] rationale... And she was kind of quite adamant about it. So... I thought to myself I'm just going to try to be transparent and curious... I found that it worked very well... and she certainly didn't feel threatened and I think in the end, it resulted in better communication between us and then a better outcome for patients in general, because we were able to... spread patients between the two clinics, which decreased one clinic from having a very heavy load unnecessarily. (RP6)

In another example, a participant was able to help a new employee to examine their communication style. They analyzed and reframed a difficult interaction using a technique learned in the RP training, and as a result, the new employee was able to improve how they interacted with patients and coworkers:

So, we sat down, she and I, and we made columns ... then, she says to herself, 'Oh my God! But what did I say there?' So, I think that this is a very concrete example that she realized herself that she had to change her way of working. (RP1)

\subsection{Impact of RP learnings on leadership skills}

The program had several impacts on the leadership skills of participants. According to the majority of them, the RP program has helped them to better support and mentor others, allowing them to become a better leader overall. It has led to 
increased confidence in themselves as leaders, and they have also been able to transfer their learnings from RP to their colleagues. For some, their RP training has helped them to confront uncomfortable issues more easily:

I'm not as afraid to confront issues as I was before, and I think that when you are going to be in a leadership position you can't just sweep everything under the rug and stay in your little corner. So I think it has given me the courage to... confront issues, work on... relationships with people... it made me a better leader. (RP3)

Another respondent was able to increase buy-in from staff, even when making an unpopular decision:

As a leader you sometimes have to turn around and say: 'I understand where you're coming from. Unfortunately, this is a decision that I have to make.' But if I can explain why I have to make the decision, sometimes that's going to make it easier for somebody to understand. (RP16)

Half of the respondents have used their RP skills to become a resource for their coworkers by sharing what they have learned and applying these skills in difficult situations. One participant stated, "it's also becoming something where people see me as a resource person. They come to see me, they come to consult me for suggestions, things like that "(RP13). Another participant used RP to help mentor and support new nurses on their unit, saying "I do use it when they come to meet to discuss cases that they're dealing with" (RP5).

Around one third of the respondents felt that the RP program has increased their confidence in their own leadership skills. One nurse leader described how they used RP principles to feel more prepared when heading into a difficult meeting: "You know how you're going to handle this meeting, and you have a strategy going in, and you have a sense of the steps that you're going to take... to get where you need to get to" (RP15).

\subsection{Impact of RP learnings on a personal level}

According to the vast majority of participants, their RP learnings had an impact on their personal lives. In particular, RP can be used to improve relations with their family members. One respondent spoke of how they reminded themselves of the "ladder of inference" when relating to their children:

You're tired after your day at work. The children are tired. Everyone is tired ... I say to myself. . . 'Relax. Go back one step and then see what has contributed to you being at the top of the [ladder of inference] and then after that, go validate the information.' (RP8)

Participants verbalized that the principles of RP were easily transferrable to the home setting: "It can be applied at home... with my husband or, you know, with my family. The theories are the same. Instead of [getting upset] right now... try to understand the person" (RP2).

\subsection{Continuance of RP program}

All of the participants called for the continuation of the RP program, citing how it gives them valuable support, tools, and structure, and has significant positive impacts on the quality of life at work:

[RP] creates an organizational culture. It is important for people to know that it is an expectation to be respectful of one another, but also to be engaged as professionals, to look at our relationships to ensure that we have a supportive environment. Work that is not just efficient, but which is efficient in the respect of everyone. (RP1)

Half of the respondents remarked about how the group training and RP meetings provide a place of support, comfort, and trust, and act as a form of self-care for them: "I feel like it's a way of looking after ourselves. It's looking after ourselves to be able to look after the others" (RP7). One participant felt that the RP program helps to decrease burnout as well, saying, "If you are able to communicate well, there is less risk of burnout because you will have less anxiety accumulation" (RP2).

Participants felt that the maintenance of the program will help to create an organizational culture that will benefit future generations of nurse leaders:

“This is a science that you can't just read about. You actually need coaches. You need to have people who mentor it. And if we don't leave that legacy... to the next generation, I think we're going to be doing them a disservice." (RP11)

\subsection{Recommendations and suggestions}

The participants made several recommendations for maintaining and improving the program, including:

- Expanding the training to other nurses and other types of professionals

- Ensuring that the composition of the groups is balanced according to the knowledge and the needs of each one in terms of RP learning 
- Protecting the time allotted for participation, to encourage better attendance

- Making sure that there is real involvement by the people in the groups, with a clear understanding of expectations about their participation in the program

- Promoting RP training and finding a way to perpetuate it

- Making RP training an organizational priority

- Succession planning for trainers/facilitators

\section{Discussion}

This study provides insight into two areas of RP nursing research which have been little-discussed until now. First, it demonstrates how when an RP program has existed on a long-term basis and is directed at nurse leaders, it manifests different benefits to its participants than programs which involve frontline staff and which have existed for a shorter period of time. Second, the study highlights how RP contributes to leadership capabilities for nurse leaders.

\subsection{Benefits of long-term participation in RP program for nurse leaders}

From the participants' perspective, it appears that the RP program is an effective way of encouraging professional development. It has provided the nurse leaders with tools and skills that they have been able to apply in their professional lives, and their statements reflect how they have been able to successfully learn and apply the key concepts, principles and techniques of the training.

Several of the benefits described by the participants have also been found in other studies looking at RP and nursing in a clinical context. For instance, participants reported that their RP training helped them to analyze and manage clinical situations more effectively, an improvement in clinical thinking skills that has also been seen in studies involving newly-graduated and pediatric critical care nurses. ${ }^{[16-18]}$ Other positive outcomes reported by participants, such as increased self-confidence and improved communication skills and teamwork, have also been reported in other studies. ${ }^{[19,20]}$ The literature suggests that some of the positive effects of RP training appear consistently, despite the differences in format or theoretical background between different programs.

However, several of the positive changes experienced by the participants are less commonly reported in the literature on RP in clinical settings. For the most part, these changes related to how they interacted with their coworkers. The majority of participants reported that they had improved their interpersonal skills, such as their ability to listen effectively, to communicate in a diplomatic and effective way, to demonstrate transparency and curiosity in their management style, and to empathize with and be compassionate towards others. Per the participants, the growth in their interpersonal skills has improved the quality-of-life and sense of collegiality at their workplace, which has spurred a wider dissemination of RP in their workplace. Participants described sharing their learning with colleagues, with several reporting that they had become a resource person on their unit due to their ability to skillfully handle difficult interpersonal situations.

The frequency with which interpersonal skills and knowledge sharing were discussed in the interviews could be related to the fact that all of the participants in this study were nurse leaders, and that they all had at least three years' experience in the program. In studies where discussion of interpersonal skills has been less prominent, the participants have been frontline staff and their involvement with RP has been for a shorter period of time. ${ }^{[17,20]}$ As leaders, the participants in this study are focused on managing the employees under their supervision, and they are often confronted with complex interpersonal conflicts that they must resolve. Their long-term involvement in the RP program means that they have had the time to familiarize themselves with the theory and practice of RP, enabling them to share their knowledge with their colleagues.

\subsection{Nurse leadership capabilities and benefits of long- term nurse leaders involvement in RP}

The impact of this RP program are highly relevant to nursing leadership. As illustrated in Figure 1, this study highlighted how the RP group helped participants to listen, understand and resolve issues from different angles. RP enabled them to analyze and manage situations and emotions from a more effective frame of mind, and to be more prepared and confident when they interact with others. These capabilities have also been identified as important by several other frameworks concerned with nursing leadership, including the LEADS program and relational leadership, as well as national and international healthcare organizations.

LEADS is a leadership capabilities framework representing the key skills, ability and knowledge required to lead at all levels of organizations and health systems, aligning and consolidating the competency frameworks and leadership strategies that are found in the health sector. ${ }^{[1]}$ The name of the program is an acronym representing key leadership capabilities (Leads Self, Engage Others, Achieves Results, Develops Coalitions). ${ }^{[21]}$ LEADS builds on the literature on leadership and leadership development in the health care sector. $^{[22]}$ 


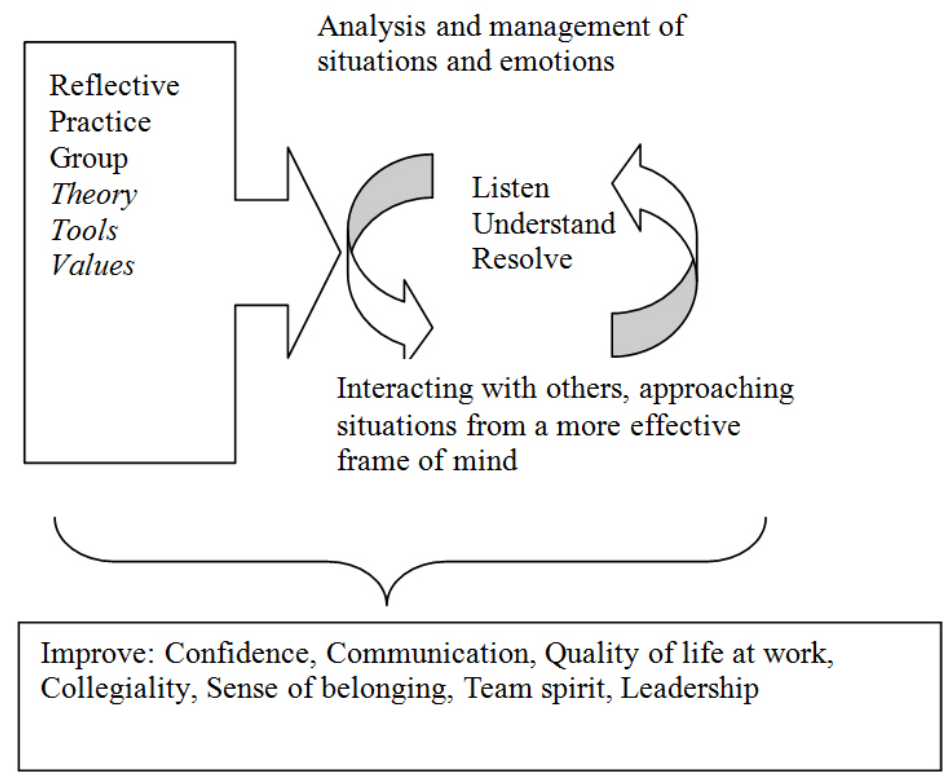

Figure 1. Reflective process at work for nurse leaders

Two of the core leadership capabilities in the LEADS framework are to effectively manage oneself (Leads Self) and make connections with other people (Engage Others), both of which have relevance to the RP program. ${ }^{[23,24]}$ In the LEADS context, Leads Self means being aware of one's own assumptions as a leader, and demonstrating qualities such as honesty and confidence. These are all skills that RP participants in this study have been able to learn and demonstrate, becoming more curious, transparent and compassionate as a result of their participation. Communicating effectively is another key to engaging others, and participants mentioned how they were able to do this by being more prepared, informed, and diplomatic, and having a better understanding of potentially difficult interactions.

Interpersonal skills are also relevant to a relational leadership framework. Relationally-focused style that is employeeoriented, with a focus on improving relationships, helping people, and increasing cooperation and teamwork, as opposed to a more task-oriented leadership style. Relational leadership involves building relationships and trust, creating an empowering work environment, creating a culture that supports knowledge development and integration, leading and sustaining change, balancing the complexities of the system, and managing competing values and priorities. ${ }^{[25]} \mathrm{A}$ relationally-focused or relationship-oriented leadership style has been associated with improved workplace environment, staff well-being, job satisfaction and patient safety. ${ }^{[26]}$

Participants also highlighted how they make better decisions, solve issues, share responsibility, and build bridges, all of which are competencies necessary for nurse leaders and man-

Published by Sciedu Press agers. As per Sullivan, ${ }^{[1]}$ competencies for nurse managers include; thinking critically, making decisions and solving problems, communicating effectively, delegating successfully, building and managing teams, handling conflict, and time-management. Communication skills are also one of the key competencies most recommended by national and international frameworks for nurse leaders. ${ }^{[2,3,27,28]}$

The RP program has given its participants a safe space to talk about emotionally-charged situations, a vocabulary with which to conceptualize their interactions, and a set of ideals to orient themselves towards better relationships. Through their participation, they have been able to bring about improvements in their work environment and share what they have learned with their colleagues. Their comments support the effectiveness of the RP program's methods for improving interpersonal and leadership skills.

\subsection{Implications}

Nurse in leadership positions need a specific body of knowledge and skills to perform their duties, yet few have the necessary training or education to be managers. Frequently, they will rely on the experiences of former supervisors or learn while on the job, indicating the existence of a gap between what managers know and what they need to know. RP programs should be implemented as a way to decrease this gap and improve leadership among nurse leaders.

\subsection{Limitations}

This study was limited by being done in only one organization. As a result, the themes which occurred may not be the same ones that would have been produced by a study in 
several organizations.

Another limitation of this study is that all of the participants were, by design, persons with at least 3 years of experience in the RP program. As such, their ability to discuss RP and its effect on their lives may be different from other participants in the program with less experience. It remains to be seen if RP has the same efficacy with nurse leaders who have had less exposure to the training.

\section{Conclusions}

These results suggest that with trained facilitators, protected time for meeting, and institutional commitment behind them, the RP program is an effective intervention for developing nursing leadership. Now, more than ever, we need knowledge, expertise and the capacity of nurses to bring solutions to current and future healthcare challenges. ${ }^{[2]}$ Complex and difficult situations are a daily reality for nurse leaders, and RP provides them with a way to respond to these situations more effectively, and to become aware of how their thinking and behavior affects their day-to-day working life. This study shows how the RP program has improved how they interact with their colleagues, creating a more positive, safe and caring environment and enabling them to be better leaders.

\section{ACKNOWLEDGEMENTS}

The McGill Nursing Collaborative for Education and Innovation in Patient-and Family-Centered Care (Newton Foundation/McGill Faculty of Medicine) for their financial support for this study; and colleagues Ron Smith, Sharyn Andrews, Alain Biron, and Catherine Oliver.

\section{CONFlicts OF InTEREST Disclosure}

The authors declare that there is no conflict of interest.

\section{REFERENCES}

[1] Sullivan EJ. Effective leadership and management in nursing. Boston: Pearson. 2017.

[2] Canadian Nursing Association. Nursing Leadership Position Statement. 2009. Available from: https: //www.cna-aiic.ca/ /media/cna/page-content/pdf -en/nursing-leadership_position-statement.pdf?la=en

[3] American Organization of Nurse Executives. AONE Nurse Manager Competencies. Chicago, IL: Author. 2015.

[4] Smith RA, Andrews S, Oliver C, et al. Putting reflective practice into action: A case study. Journal of Nursing Education and Practice. 2018; 8(10): 36-47. https ://doi.org/10.5430/jnep.v8n10p3 6

[5] Argyris C, Schon DA. Theory in practice: Increasing professional effectiveness. San Francisco: Jossey-Bass Publishers; 1974.

[6] Schön D. The reflective practitioner: How professionals think in action. New York: Basic Books; 1983.

[7] Schon D. Educating the reflective practitioner : Toward a new design for teaching and learning in the professions. 1st ed. The Jossey-Bass higher education series. San Francisco: Jossey-Bass; 1987.

[8] Argyris C. Learning and Teaching: A Theory of Action Perspective. Journal of Management Education. 1997; 21(1): 9-26. https : //doi.org/10.1177/105256299702100102

[9] Schwarz R. The skilled facilitator: A comprehensive resource for consultants, facilitators, coaches, and trainers. 3rd ed. Hoboken, NJ, USA: John Wiley \& Sons, Inc. 2017.

[10] Kegan R, Lahey LL. Immunity to change: How to overcome it and unlock potential in yourself and your organization. Boston, Mass: Harvard Business Press; 2009.

[11] Kegan R, Laskow LL. An everyone culture: Becoming a deliberately developmental organization. Boston, Mass: Harvard Business Press; 2016.

[12] Dubé V, Ducharme F. Nursing reflective practice: An empirical literature review. Journal of Nursing Education and Practice. 2015; 5(7): 91-99. http://dx.doi.org/10.5430/jnep.v5n7p91
[13] Smith RA. A reflective practice approach to professional development. In K.T. Brinko (Ed.), Practically speaking: A sourcebook for instructional consultants in higher education. Stillwater, OK: New Forums Press; 2012.

[14] Sandelowski M. Focus on research methods: Whatever happened to qualitative description? Research in Nursing and Health. 2000; 23(4), 334-340. https://doi.org/10.1002/1098-240X (200008)23: 4<334: : AID-NUR9>3.0. CO;2-G

[15] Miles MB, Huberman AM. Qualitative data analysis: An expanded sourcebook. Sage; 1994.

[16] Forneris SG, Peden-McAlpine C. Evaluation of a reflective learning intervention to improve critical thinking in novice nurses. Journal of Advanced Nursing. 2007; 57(4): 410-421. PMid:17291205 https://doi .org/10.1111/j.1365-2648.2007.04120.x

[17] Goudreau J, Pepin J, Larue C, et al. A competency-based approach to nurses' continuing education for clinical reasoning and leadership through reflective practice in a care situation. Nurse Education in Practice. 2015; 15(6): 572-578. PMid:26559351 https: //doi.org/10.1016/j.nepr.2015.10.013

[18] Peden-McAlpine C, Tomlinson PS, Forneris SG, et al. Evaluation of a reflective practice intervention to enhance family care. Journal of Advanced Nursing. 2005; 49(5): 494-501. PMid:15713181 https://doi.org/10.1111/j.1365-2648.2004.03322.x

[19] Kemp P, Rooks J, Mess L. Work-based learning with staff in an acute care environment: a project review and evaluation. Mental Health Practice. 2009; 12(10): 31-35. https://doi.org/10.7748/mhp2 $009.07 .12 .10 .31 . c 7870$

[20] McDonald G, Jackson D, Wilkes L, et al. A work-based educational intervention to support the development of personal resilience in nurses and midwives. Nurse Education Today. 2012; 32(4): 378-384. PMid:21724307 https://doi.org/10.1016/j.nedt. 2011.04 .012

[21] Vilches S, Fenwick S, Harris B, et al. Changing health organizations with the LEADS leadership framework: Report of the 2014-2016 LEADS impact study. Ottawa, Canada: Fenwick Leadership Explorations, the Canadian College of Health Leaders, \& the Centre for Health Leadership and Research, Royal Roads University. 2016. 
Available from: https://leadscanada.net/document/1789/ Mitacs_LEADS_Summary_Report_EN_2017_FINAL.pdf

[22] Canadian Health Network Leadership. LEAD Framework \& Tools. 2017. Available from: http://chlnet.ca/tools-resources/l eads-framework

[23] Canadian College of Health Leaders. 2010. Engage others. 2013. Available from: https://leadersforlife.ca/uploaded/web /Resources/summaries/EN/LEADS_EngageOthers_Executi veSummary_EN_2.pdf

[24] Canadian College of Health Leaders. Lead self. 2010. Available from: https://leadersforlife.ca/uploaded/web/Resourc es/summaries/EN/LEADS_LeadSelf_ExecutiveSummary_EN $-2 \cdot \mathrm{pdf}$
[25] Sellgren SF, Ekvall G, Tomson G. Leadership behaviour of nurse managers in relation to job satisfaction and work climate. Journal of Nursing Management. 2008; 16(5): 578-587.

[26] Wong CA, Cummings GG, Ducharme L. The relationship between nursing leadership and patient outcomes: A systematic review update. Journal of Nursing Management. 2013; 21(5): 709-724. PMid:23865924 https://doi.org/10.1111/jonm.12116

[27] Registered Nurses' Association of Ontario. Developing and Sustaining Nursing Leadership. 2nd ed. Toronto, ON: Registered Nurses' Association of Ontario. This work is funded by the Ontario Ministry of Health and Long-Term Care. 2013.

[28] World Health Organization. Nurse Educator Core Competencies. 2016. Available from: http://www.who.int/hrh/nursing_mi dwifery/nurse_educator050416.pdf?ua=1 